\title{
Molecular and Serological Evidence for the Presence of Novel Phleboviruses in Sandflies from Northern Algeria
}

\author{
Grégory Moureau $^{1}$, Laurence Bichaud ${ }^{1}$, Nicolas Salez $^{1}$, Laetitia Ninove $^{1}$, Boussad Hamrioui ${ }^{2}$, \\ Smail Belazzoug ${ }^{3}$, Xavier de Lamballerie ${ }^{1}$, Arezki Izri ${ }^{4}$ and Rémi N. Charrel ${ }^{*}, 1$ \\ ${ }^{1}$ Unité des Virus Emergents (UMR190) Université de la Méditerranée - Institute of Research for Development, \\ Marseille, France \\ ${ }^{2}$ Université d'Alger, Alger, Algeria \\ ${ }^{3}$ Laboratoire d'Analyses médicales Bou-Ismail 40 Lot Polyclinique Tipaza, Algérie \\ ${ }^{4}$ Université Paris 13, UFR Bobigny, France
}

\begin{abstract}
During summer 2007, a total of 785 phlebotomine flies were trapped in northern Algeria, identified morphologically, organised as monospecific pools and tested for the presence of phlebovirus RNA using degenerate primers. Three pools were positive, and the corresponding PCR products were cloned and sequenced. Viral sequences corresponding to two phleboviruses distinct from each other were detected in sandflies circulating in two close locations (140 km apart) in Northern Algeria. The 3 sequences were aligned with homologous polymerase sequences retrieved from the Genbank database, in order to examine their phylogenetic relationships. One viral sequence (from Phlebotomus papatasi) was closely related to but distinct from a sequence obtained from Phlebotomus ariasi sandflies trapped in Algeria in 2006. The two other viral sequences (from Phlebotomus longicuspis) were genetically distantly related to sequences corresponding to virus members of the Sandfly fever Naples virus species and although falling within the same group, this clearly represents a second distinct novel lineage. These results are indicative of a high genetic heterogeneity within sandflies trapped in a relatively small geographic area. Seroprevalence studies conducted on sera from populations living in the same areas indicated that humans can be infected by these viruses.
\end{abstract}

Keywords: Toscana virus, Punique virus, sandfly fever sicilian virus, sandfly fever Naples virus, emergence, mediterranean.

\section{INTRODUCTION}

Recent field and experimental studies have provided increasing evidence that the number of known viruses in the genus Phlebovirus (Bunyaviridae family) may be largely underestimated as suggested by phylogram shape-based analyses [1-3]. Until recently, sandflies distributed in the old world were known as vectors for few phleboviruses including two known species (Sandfly fever Naples virus, and Salehebad virus), and tentative species such as sandfly fever Sicilian virus and Corfou virus.

During the last decade, Toscana virus, a member of the species Sandfly fever Naples virus (SFNV), was increasingly investigated in patients presenting with febrile neurological manifestations (meningitis, encephalitis) during the summer in Mediterranean countries. The focus on Toscana virus occurred in the mid 1990's with several studies from central Italy where this virus was shown to be the most frequent cause of meningitis in central Italy during summertime [4-6]. The second event which highlighted Toscana virus was the systematic surveillance initiated in many South-European countries to track West Nile virus after it invaded the United

*Address correspondence to this author at the Unite des Virus Emergents, UMR190 "Emergence des Pathologies Virales, Faculte de Medecine, 27, blvd Jean Moulin, 13005 Marseille, France; Tel: +33 (0)4 913244 20; Fax: +33 (0)4 913244 21; E-mail: remi.charrel@univmed.fr
States in 1999 and caused outbreaks in Europe and North Africa [7, 8]. Surveillance for West Nile virus infections demonstrated that Toscana virus, whose prevalence was also assessed by reference laboratories, (i) was much more prevalent than West Nile virus, (ii) much more prevalent than initially believed, (iii) and circulated and caused human infections in Spain, France, and Portugal, and probably many other countries where sandflies are distributed [9-15].

Sandfly fever Sicilian virus (SFSV) is a distinct arthropod-borne phlebovirus transmitted by sandflies, specifically by Phlebotomus papatasi [16]. It was discovered in Italy (Palerma, Sicilia) where it affected the troops of the Allied Army Forces after the Sicily landings in 1943 during World War II. Clinical presentation is a febrile illness during the warm season; in contrast with Toscana virus infection, SFSV has not been associated with neurological manifestations. Recently, molecular evidence for the presence of a phlebovirus closely related to Sandfly fever Sicilian virus (SFSV) in Algeria was reported [3].

Recently, the novel Massilia virus, was discovered in sandflies from southeastern France [2].

Taken together, these recent findings led us to conduct field investigations in Algeria, a North African country where high densities of sandflies have been reported, and where they are associated with cutaneous and visceral leishmaniasis $[17,18]$. 


\section{MATERIALS AND METHODOLOGY}

\section{Sandfly Trapping and Morphological Identification}

In July 2007, sandflies were trapped in northern Algeria using previously described methodology [14]. Trapping was performed at two sites: (i) Larbaa Nath Iraten (previously known as Fort National) in the Kabylian region of Algeria, close to Tizi Ouzou, (ii) and Bou Ismail, in the vicinity of Alger, the capital city. CDC Miniature Light Traps were adapted to sandflies capture by using an ultra-fine mesh. Traps were placed between one and two meters above the ground. They were set during the late afternoon in the vicinity of or in animal housing facilities (sheep, goats, rabbits, chicken). Each morning, sandflies were collected, identified morphologically, and placed in $1.5 \mathrm{~mL}$ microfuge tubes. They were organized in monospecific pools according to sex and trapping area, each pool containing up to 30 entire sandflies. Pools were individually ground in RNA Now, a chaotropic solution containing guanidinium thiocyanate (Ozyme, Montigny Le Bretonneux, France) due to a lack of dry ice or liquid nitrogen for preservation.

\section{Virology and Phylogenetic Analysis}

RNA Now-based viral RNA purification was conducted according to the manufacturer's protocol (Ozyme). A total of $10 \mu \mathrm{L}$ of RNA was used for RT-PCR in a final volume of 50 $\mu \mathrm{L}$ as previously described [19]. RT-PCR reactions were performed using the Access RT-PCR System kit (Promega France, Charbonnières). Positive PCR products of the expected size were gel-purified, cloned and sequenced in both directions. Resulting sequences were aligned together with homologous sequences of selected members of the genus Phlebovirus retrieved from Genbank. Genbank accession numbers are shown in Fig. (2). Sequences obtained in this study were compiled with those from Genbank to perform genetic distance comparison and phylogenetic analysis. Distance matrices were calculated for each novel sequence independently. Pairwise distance and groupings were determined via neighbor-joining method within the MEGA 4.0 software program [20]. The robustness of the groupings was tested by using 1000 bootstrap pseudoreplications. Due to the preservation technique, it was impossible to attempt virus isolation on cell culture.

\section{Human Sera}

Two series of human sera were available for seroprevalence studies: (i) 60 samples from healthy persons living in Kabylia in the vicinity of the area where sandflies were trapped, (ii) 104 samples from patients living in the city of Alger who presented at a private biological laboratory for reasons not specifically related to febrile illness.

\section{Serology}

Immunoglobulin (Ig) $\mathrm{G}$ and $\mathrm{M}$ were detected by indirect immunofluorescence (IIF) assay as previously described [21] with minor modifications. Briefly, equal amounts of infected and uninfected Vero cells were mixed together and spotted onto 2-well glass slides through a 3-min cytospin-based centrifugation at $900 \mathrm{rpm}$. Samples were tested at 1:20 dilution in phosphate-buffered saline. The presence of uninfected Vero cells allowed to detect non specific fluorescence (all cells were fluorescent). Sera were tested by IgG and IgM enzyme-linked immunosorbent assay (ELISA) with the Toscana virus - Enzywell Toscana virus (recombinant nucleoprotein) IgG and IgM - DIESSE Diagnostica Senese S.p.A, (Siena, Italy) using the protocol recommended by the manufacturer. A serum was considered positive in either IgG or IgM if both ELISA and IIF were positive.

\section{RESULTS}

The two trapping sites are shown in Fig. (1). A total of 785 sandflies were trapped, processed individually for morphological identification, organized into 40 pools, and used for viral RNA detection (Table 1). A total of 3 pools tested positive with nested primers NPhlebo2+ / NPhlebo2-. A 201-nt sequence (excluding primers) was obtained. These 3 sequences were deposited in Genbank with accession numbers GU183867-183869. Nucleotide and amino acid distances are presented in Table 2 . The two sequences obtained from Phlebotomus longicuspis were most closely related to the Poona strain of SFNV, and clearly belonged to the species SFNV, with an amino acid and nucleotide distance comprised between 9 to $37.3 \%$ and 1 to $34.8 \%$ respectively. The sequence determined from Phlebotomus papatasi was most closely related to Cyprus virus and not to the SFSV-like phlebovirus previously discovered in Algeria in 2006. However, these 4 sequences formed a cluster together with the sequence of the prototype Sabin strain of SFSV, with pairwise amino acid and nucleotide distances lower than $6 \%$ and $20 \%$, respectively.

The two seroprevalence studies indicated that the presence of IgG specific of SFNV or SFN-like virus was observed at rates of $10.6 \%(11 / 104$ sera) and $21.6 \%(13 / 60$ sera) originating from Bou Ismail and Larbaa Nath Iraten areas, respectively. In the Bou Ismail subset, the mean age of seropositives was 49 while the mean age of the total population was 37 .

\section{DISCUSSION}

Recent investigations of sandfly-transmitted phleboviruses have indicated that virus diversity within the Mediterranean is higher than initially suspected, and that local populations have a high risk of infection during their lifetime $[2,3,14,22-24]$. These recent data suggest that sandfly associated viral infections may also be a concern for public health in regions located south of the Mediterranean, where high densities of sandflies are reported. For these reasons, we decided to conduct investigations based on a transversal approach involving at first a combination of entomological and virological studies, and seroprevalence studies on populations living in the area where sandflies were trapped. A total of one and two pools were found to contain SFS- and SFN-like virus RNA, respectively. Human infection due to these viruses was supported by seroprevalence studies indicating rates varying from 5\% for SFS-like virus [3] and 10.6-21.6\% for SFN-like virus (this study). The new SFS-like virus was detected in Phlebotomus papatasi and showed to be closely related to, but distinct from, SFSV previously detected in Phlebotomus ariasi from Algeria [3], and from Cyprus virus isolated from humans [23-25]. 


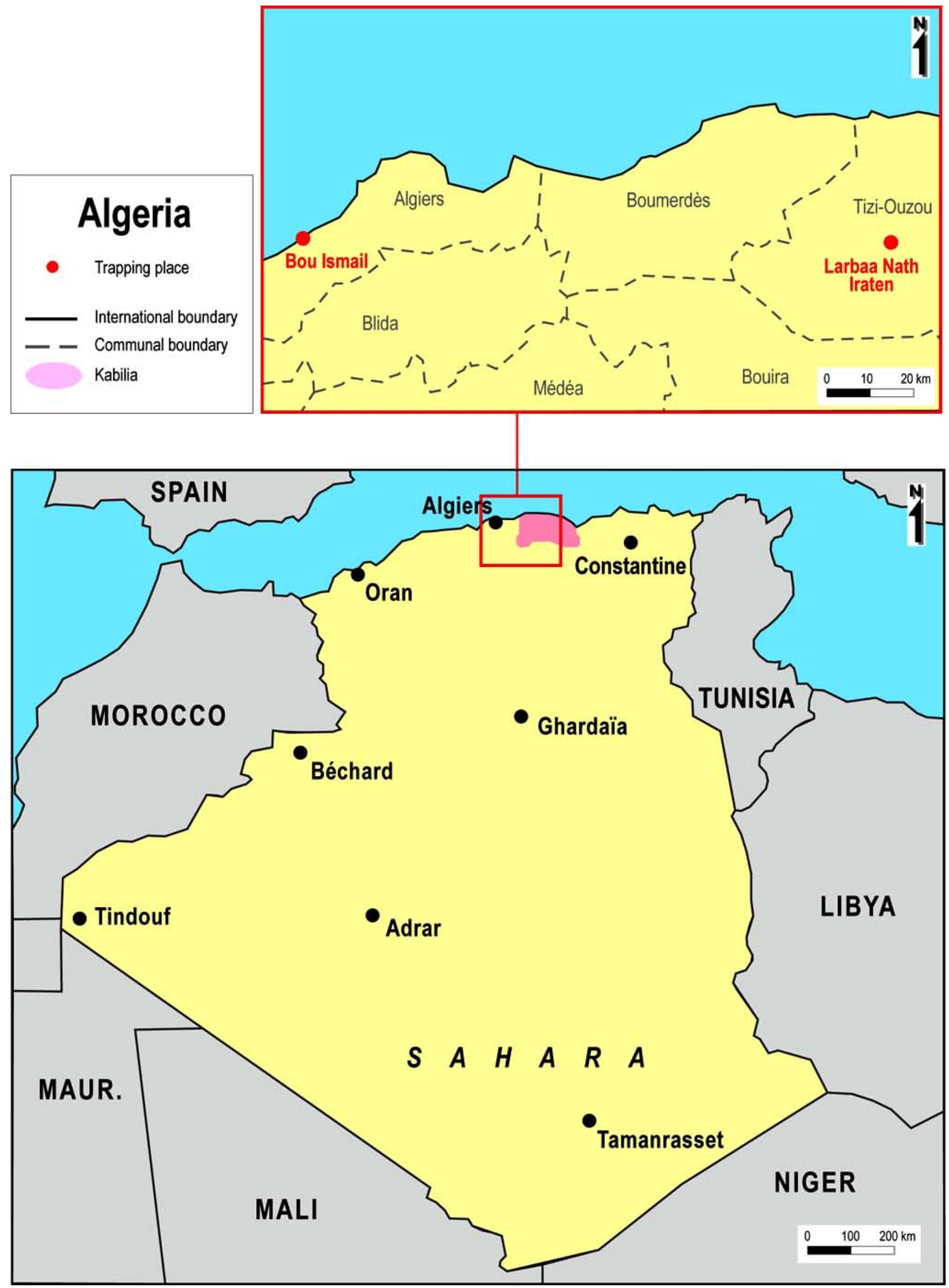

Fig. (1). Geographic Trapping locations in Algeria. 
Table 1. Sandfly Trapping and Identification

\begin{tabular}{|c|c|c|c|c|}
\hline Trapping Region & Species & Gender & No. Sandflies & No. Pools \\
\hline \multirow{13}{*}{ Larbaa Nath Iraten } & \multirow{2}{*}{ Phlebotomus longicuspis } & M & 17 & 1 \\
\hline & & $\mathrm{F}$ & 48 & 2 \\
\hline & \multirow{2}{*}{ Phlebotomus papatasi } & $\mathrm{M}$ & 1 & $1 *$ \\
\hline & & $\mathrm{F}$ & 6 & 2 \\
\hline & \multirow{2}{*}{ Phlebotomus perfiliewi } & $\mathrm{M}$ & 4 & 1 \\
\hline & & $\mathrm{F}$ & 0 & 0 \\
\hline & \multirow{2}{*}{ Phlebotomus perniciosus } & $\mathrm{M}$ & 261 & 9 \\
\hline & & $\mathrm{F}$ & 120 & 4 \\
\hline & \multirow{2}{*}{ Phlebotomus sergenti } & $\mathrm{M}$ & 7 & 1 \\
\hline & & $\mathrm{F}$ & 5 & 1 \\
\hline & \multirow{2}{*}{ Sergentomyia minuta } & $\mathrm{M}$ & 0 & 0 \\
\hline & & $\mathrm{F}$ & 2 & 1 \\
\hline & TOTAL Larba Nath Iraten & & 471 & 23 \\
\hline \multirow{9}{*}{ Bou Ismail } & \multirow{2}{*}{ Phlebotomus longicuspis } & $\mathrm{M}$ & 84 & 4 \\
\hline & & $\mathrm{F}$ & 149 & $6 * *$ \\
\hline & \multirow{2}{*}{ Phlebotomus papatasi } & $\mathrm{M}$ & 21 & 1 \\
\hline & & $\mathrm{F}$ & 25 & 1 \\
\hline & \multirow{2}{*}{ Phlebotomus perniciosus } & $\mathrm{M}$ & 6 & 1 \\
\hline & & $\mathrm{F}$ & 7 & 1 \\
\hline & \multirow{2}{*}{ Sergentomyia minuta } & $\mathrm{M}$ & 18 & 2 \\
\hline & & $\mathrm{F}$ & 2 & 1 \\
\hline & TOTAL Bou Ismail & & 314 & 17 \\
\hline TOTAL & & & 785 & 40 \\
\hline
\end{tabular}

*Indicates the number of pools tested positive for phlebovirus RNA by PCR ( 1 * Corresponds to 1 positive pool, ** Corresponds to 2 positive pools).

Table 2. Pairwise Genetic Distances Between (A) Sandfly Fever Naples Virus Group and (B) Sandfly Fever Sicilian Virus Group Against other Member of the Genus Phlebovirus Included in the Study

Table 2A

\begin{tabular}{|c|c|c|c|c|c|c|c|c|c|c|c|}
\hline No. & Virus & 1 & 2 & 3 & 4 & 5 & 6 & 7 & 8 & 9 & Others \\
\hline \multicolumn{12}{|c|}{ Nucleotide sequences } \\
\hline 1 & $\begin{array}{l}\text { SFNV } \\
\text { Algeria_A5_Ph_longicuspis } \\
\text { GU183867 }\end{array}$ & - & 0.010 & 0.343 & 0.249 & 0.010 & 0.294 & 0.348 & 0.308 & 0.308 & $0.428-0.602$ \\
\hline 2 & $\begin{array}{l}\text { SFNV } \\
\text { Algeria_A6_Ph_longicuspis } \\
\text { GU183868 }\end{array}$ & 0.000 & - & 0.348 & 0.249 & 0.000 & 0.294 & 0.348 & 0.308 & 0.308 & $0.418-0.597$ \\
\hline 3 & SFNV Massilia_W EU725771 & 0.373 & 0.373 & - & 0.368 & 0.293 & 0.279 & 0.315 & 0.285 & 0.290 & $0.332-0.580$ \\
\hline 4 & SFNV 30451 GQ165528 & 0.090 & 0.090 & 0.358 & - & 0.249 & 0.249 & 0.313 & 0.308 & 0.308 & $0.428-0.552$ \\
\hline 5 & SFNV Poona EF095548 & 0.000 & 0.000 & 0.230 & 0.090 & - & 0.267 & 0.284 & 0.273 & 0.265 & $0.349-0.586$ \\
\hline 6 & SFNV Tehran_I_47 GQ165522 & 0.209 & 0.209 & 0.190 & 0.164 & 0.155 & - & 0.246 & 0.259 & 0.259 & $0.352-0.572$ \\
\hline 7 & $\begin{array}{l}\text { SFNV Toscana_AR_France } \\
\text { DQ65607 }\end{array}$ & 0.254 & 0.254 & 0.195 & 0.194 & 0.186 & 0.149 & - & 0.159 & 0.153 & $0.340-0.579$ \\
\hline 8 & $\begin{array}{l}\text { SFNV Toscana_ISS.Phl.3 } \\
\text { NC_0063 }\end{array}$ & 0.254 & 0.254 & 0.184 & 0.209 & 0.186 & 0.143 & 0.027 & - & 0.017 & $0.356-0.573$ \\
\hline 9 & $\begin{array}{l}\text { SFNV } \\
\text { Toscana_France_1500590 } \\
\text { DQ975233 }\end{array}$ & 0.254 & 0.254 & 0.198 & 0.209 & 0.181 & 0.143 & 0.034 & 0.006 & - & $0.348-0.583$ \\
\hline Others & & $0.448-0.716$ & $\begin{array}{l}0.448- \\
0.716\end{array}$ & $\begin{array}{l}0.463- \\
0.716\end{array}$ & $\begin{array}{l}0.433- \\
0.731\end{array}$ & $\begin{array}{c}0.448- \\
0.696\end{array}$ & $0.403-0.726$ & $\begin{array}{c}0.403- \\
0.699\end{array}$ & $\begin{array}{c}0.403- \\
0.699\end{array}$ & $\begin{array}{l}0.316- \\
0.709\end{array}$ & - \\
\hline \multicolumn{12}{|c|}{ Amino acid sequences } \\
\hline
\end{tabular}


(Table 2) contd.....

Table 2B

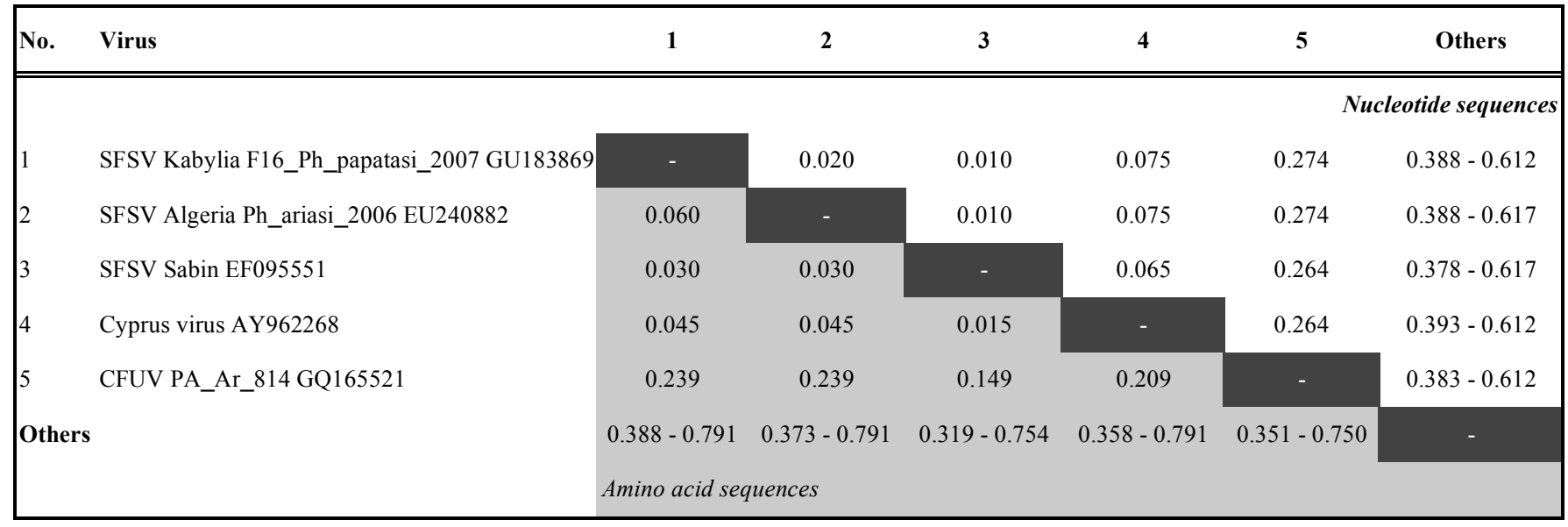

Since detection of viral sequences could not be confirmed through virus isolation, it is necessary to address the question of potential contamination. Concerning the two SFN-like phleboviruses, the sequences are genetically sufficiently distinct from other sequences determined in our unit during the last 3 years (underlined in the Fig. 2) to exclude laboratory contamination. Moreover, the genetic variation inside the Sandfly fever Naples group is much larger than determined in our previous study [2]. Based on the polymerase gene, the genetic distance between this newly discovered strain of Sandfly fever Naples in Algeria and Massilia virus is $37.3 \%$ and $34.3 \%$ for amino acids and nucleotide data respectively. The novel SFSV-like sequence obtained in this study from the Phlebotomus papatasi pool is genetically divergent at $4 \mathrm{nt}$ sites and 4 AA sites from sequences previously determined from a pool of Phlebotomus patatasi in our laboratory in 2007 [3] and at 2 nt sites and 2 AA sites from Sandfly fever Sicilian strain Sabin. Furthermore, detailed analysis of the relevant chromatograms supports this clear divergence.

\section{SFSV and SFS-Like Viruses}

Human cases of SFSV infection have been reported from Italy, Egypt, Pakistan, Iran and Cyprus [16, 23]. Seroprevalence studies performed with human or vertebrate sera indicates that SFSV, or a closely related one, is circulating in Jordan [26], Israel [27], Sudan [28], Tunisia [29], Pakistan [30], Egypt [31], Bangladesh [32], Iran [33]. At the outset of this study, the most comprehensive serological study did not detect the presence of neutralizing antibodies reactive to SFSV in human sera of Algerian populations of Tamanrasset and Djanet [34]. However, these two areas are located at the southern border of Algeria in arid environment. Detection of SFS-like RNA in this study corroborates previous findings concerning the presence of a new phlebovirus closely related to but distinct from SFSV and Cyprus virus. It is likely that the Algerian SFS-like virus infects humans according to serology results previously reported [3].

\section{SFNV and SFN-Like Viruses}

Human cases of SFNV, mostly caused by Toscana virus, based on virus isolation and/or molecular evidence have been reported from North Mediterranean counties [6, 13-15, 24, 35-38]. The original Naples virus was identified for the last time in 1985 in Egypt from a human specimen [39]. For the last two decades, Toscana virus was the only genotype of the SFNV species to have been detected and/or isolated in relation to human cases [22]. Seroprevalence studies performed with human sera indicate that SFNV, or a closely related virus, is circulating in Ethiopia, Sudan, Egypt, Morocco, Greece, former Yugoslavia, Turkey, Iraq, Saudi Arabia, Iran, former USSR [Moldavia, Azerbaijan, Uzbekistan, Tajikistan, Turkmenistan], Pakistan and Bangladesh [34]. More recently, seroprevalence studies indicated that Toscana virus, or an antigenically closelyrelated virus, circulates in Spain [9], France [40], Italy [38, 41], and Cyprus [42]. In contrast, low prevalence of antibody was observed in Germany [43]. The most comprehensive serological study did not detect the presence of neutralizing antibodies reactive to SFNV or SFN-like virus in human sera of Algerian populations of Tamanrasset and Djanet [34]. Therefore, at the outset of this study, there was neither molecular evidence nor serology-based data suggesting the presence of SFNV in Algeria. To our knowledge, this is the first time (i) that SFN-like virus has been detected in Algeria, (ii) and that indirect evidence via seroprevalence studies, is reported. Discrepancy between the mean age of the tested population and that of seropositive individuals is indicative that the longer the exposure, the higher the risk of getting infected by SFNV or SFN-like virus.

Together, molecular and serological data provided here constitute evidence that novel phleboviruses distinct from but related to SFSV and SFNV are present in Algeria, and can infect humans.

\section{ACKNOWLEDGEMENTS}

This work was partially supported by the French Research Agency (ANR) through the PhleboMED project, 


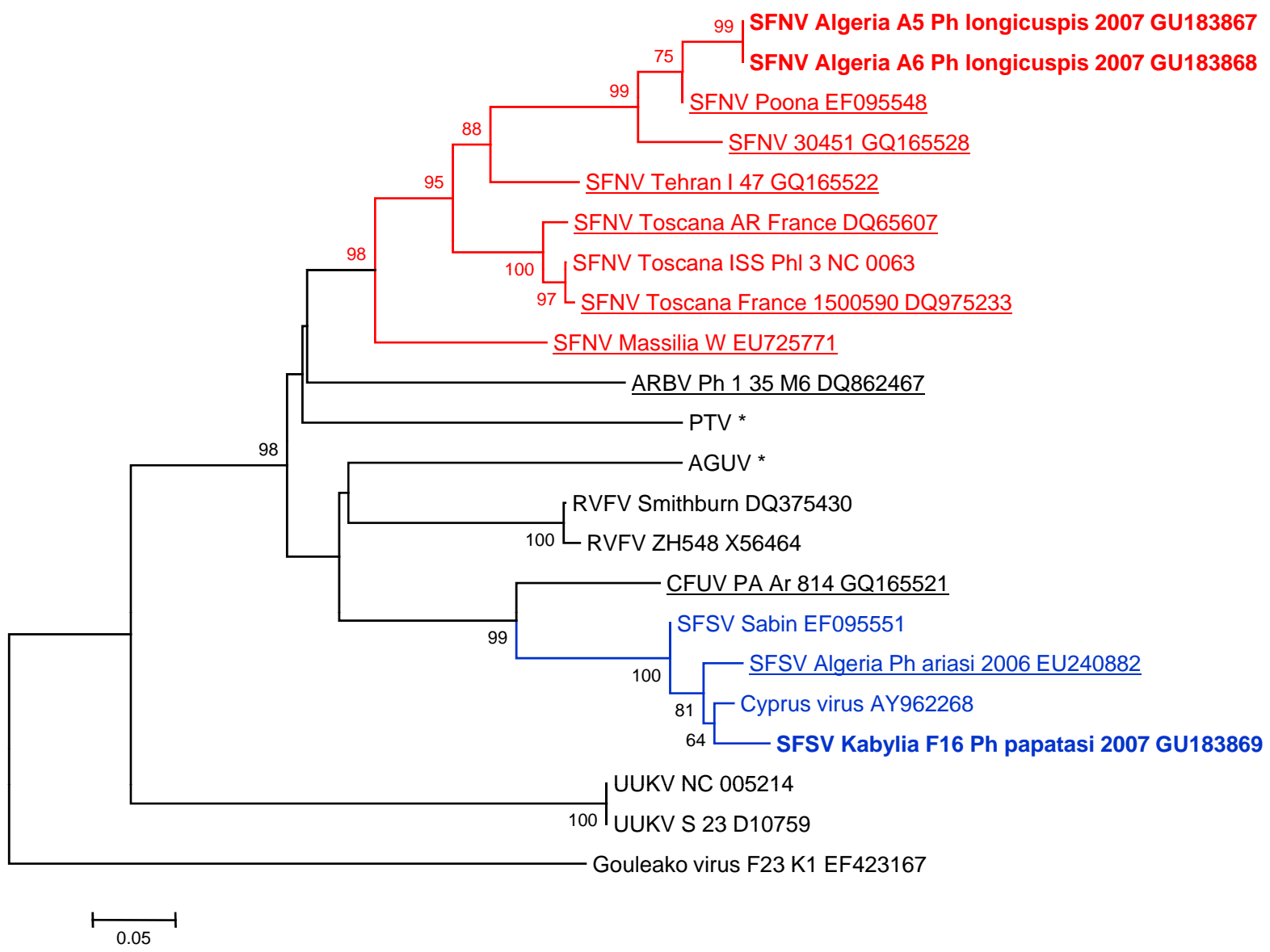

Sequences determined in this study are bolded, sequences determined previously in our laboratory are underlined, PTV and AGUV sequences were kindly provided by Dr Maria Paz Sanchez -Seco, Madrid. In blue, sequences corresponding to sandfly fever Sicilian (SFS) and SFS -like viruses, in red, sequences corresponding to sandfly fever Naples (SFN) and SFN -like viruses.

Fig. (2). Phylogenetic analysis of phlebovirus sequences obtained from Algerian sandflies based on 67-AA sequence representing a section of the polymerase gene. Distances and groupings were determined by the pairwise or kimura-2 algorithm and neighbor-joining method within MEGA 4.0 [20]. Bootstrap values corresponding to 1000 replications are indicated. Sequences determined in this study are bolded.

the FP7 European project $n^{\circ} 228292$ EVA (European Virus Archive). The authors thank Fabienne Pinna for preparing the immunofluorescence slides.

\section{REFERENCES}

[1] Pybus OG, Rambaut A, Holmes EC, Harvey PH. New inferences from tree shape: numbers of missing taxa and population growth rates. Syst Biol 2002; 51: 881-8.

[2] Charrel RN, Moureau G, Temmam S, et al. Massilia virus, a novel Phlebovirus (Bunyaviridae) isolated from sandflies in the Mediterranean. Vector Borne Zoonotic Dis, Larchmont, NY 2009; 9: 519-30.

[3] Izri A, Temmam S, Moureau G, Hamrioui B, de Lamballerie X, Charrel RN. Sandfly fever Sicilian virus, Algeria. Emerg Infect Dis 2008; 14: 795-7.

[4] Braito A, Ciufolini MG, Pippi L, et al. Phlebotomus-transmitted toscana virus infections of the central nervous system: a seven-year experience in Tuscany. Scand J Infect Dis 1998; 30: 505-8.

[5] Nicoletti L, Verani P, Caciolli S, et al. Central nervous system involvement during infection by Phlebovirus toscana of residents in natural foci in central Italy (1977-1988). Am J Trop Med Hyg 1991; 45: 429-34.

[6] Valassina M, Meacci F, Valensin PE, Cusi MG. Detection of neurotropic viruses circulating in Tuscany: the incisive role of Toscana virus. J Med Virol 2000; 60: 86-90.
[7] Briese T, Jia XY, Huang C, Grady LJ, Lipkin WI. Identification of a Kunjin/West Nile-like flavivirus in brains of patients with New York encephalitis. Lancet 1999; 354: 1261-2.

[8] Granwehr BP, Lillibridge KM, Higgs S, et al. West Nile virus: where are we now? Lancet Infect Dis 2004; 4: 547-56.

[9] Mendoza-Montero J, Gamez-Rueda MI, Navarro-Mari JM, de la Rosa-Fraile M, Oyonarte-Gomez S. Infections due to sandfly fever virus serotype Toscana in Spain. Clin Infect Dis 1998; 27: 434-6.

[10] Echevarria JM, de Ory F, Guisasola ME, et al. Acute meningitis due to Toscana virus infection among patients from both the Spanish Mediterranean region and the region of Madrid. J Clin Virol 2003; 26: 79-84

[11] Navarro JM, Fernandez-Roldan C, Perez-Ruiz M, Sanbonmatsu S, de la Rosa M, Sanchez-Seco MP. Meningitis by Toscana virus in Spain: description of 17 cases. Med Clin (Barc) 2004; 122: 420-2

[12] Hemmersbach-Miller M, Parola P, Charrel RN, Paul Durand J, Brouqui P. Sandfly fever due to Toscana virus: an emerging infection in southern France. Eur J Intern Med 2004; 15: 316-7.

[13] Peyrefitte CN, Devetakov I, Pastorino B, et al. Toscana virus and acute meningitis, France. Emerg Infect Dis 2005; 11: 778-80.

[14] Charrel RN, Izri A, Temmam S, et al. Cocirculation of 2 genotypes of Toscana virus, southeastern France. Emerg Infect Dis 2007; 13: 465-8.

[15] Santos L, Simoes J, Costa R, Martins S, Lecour H. Toscana virus meningitis in Portugal, 2002-2005. Euro Surveill 2007; 12: E3-4. 
[16] Karabatsos N. International Catalogue of Arthropod-borne viruses. $3^{\text {rd }}$ ed. American Society for Tropical Medicine and Hygiene. San Antonio, Texas: 1985; Suppl 1: pp. 137-52.

[17] Dedet JP. Stages in the identification of phlebotomine sandflies as vectors of leishmaniases and other tropical diseases. Parassitologia 2005; 47: 291-5.

[18] Harrat Z, Pratlong F, Belazzoug S, et al. Leishmania infantum and L. major in Algeria. Trans R Soc Trop Med Hyg 1996; 90: 625-9.

[19] Sanchez-Seco MP, Echevarria JM, Hernandez L, Estevez D, Navarro-Mari JM, Tenorio A. Detection and identification of Toscana and other phleboviruses by RT-nested-PCR assays with degenerated primers. J Med Virol 2003; 71: 140-9.

[20] Tamura K, Dudley J, Nei M, Kumar S. MEGA4: Molecular Evolutionary Genetics Analysis (MEGA) software version 4.0. Mol Biol Evol 2007; 24: 1596-9.

[21] Fulhorst CF, Monroe MC, Salas RA, et al. Isolation, characterization and geographic distribution of Cano Delgadito virus, a newly discovered South American hantavirus (family Bunyaviridae). Virus Res 1997; 51: 159-71.

[22] Charrel RN, Gallian P, Navarro-Mari JM, et al. Emergence of Toscana virus in Europe. Emerg Infect Dis 2005; 11: 1657-63.

[23] Papa A, Konstantinou G, Pavlidou V, Antoniadis A. Sandfly fever virus outbreak in Cyprus. Clin Microbiol Infect 2006; 12: 192-4.

[24] Sanbonmatsu-Gamez S, Perez-Ruiz M, Collao X, et al. Toscana virus in Spain. Emerg Infect Dis 2005; 11: 1701-7.

[25] Konstantinou GN, Papa A, Antoniadis A. Sandfly-fever outbreak in Cyprus: are phleboviruses still a health problem? Travel Med Infect Dis 2007; 5: 239-42.

[26] Batieha A, Saliba EK, Graham R, Mohareb E, Hijazi Y, Wijeyaratne P. Seroprevalence of West Nile, Rift Valley, and sandfly arboviruses in Hashimiah, Jordan. Emerg Infect Dis 2000; 6: 358-62.

[27] Cohen D, Zaide Y, Karasenty E, et al. Prevalence of antibodies to West Nile fever, sandfly fever Sicilian, and sandfly fever Naples viruses in healthy adults in Israel. Public Health Rev 1999; 27: 217 30.

[28] McCarthy MC, Haberberger RL, Salib AW, et al. Evaluation of arthropod-borne viruses and other infectious disease pathogens as the causes of febrile illnesses in the Khartoum Province of Sudan. J Med Virol 1996; 48: 141-6.

[29] Chastel C, Bach-Hamba D, Launay H, Le Lay G, Hellal H, Beaucournu JC. [Arbovirus infections in Tunisia: new serological survey of small wild mammals]. Bull Soc Pathol Exot Filiales 1983; 76: 21-33.

[30] Darwish MA, Hoogstraal H, Roberts TJ, Ghazi R, Amer T. A seroepidemiological survey for Bunyaviridae and certain other arboviruses in Pakistan. Trans R Soc Trop Med Hyg 1983; 77: 44650 .

[31] Darwish MA, Feinsod FM, Scott RM, et al. Arboviral causes of non-specific fever and myalgia in a fever hospital patient population in Cairo, Egypt. Trans R Soc Trop Med Hyg 1987; 81: 1001-3.

[32] Gaidamovich SY, Baten MA, Klisenko GA, Melnikova YE. Serological studies on sandfly fevers in the Republic of Bangladesh. Acta Virol 1984; 28: 325-8.

[33] Saidi S, Tesh R, Javadian E, Sahabi Z, Nadim A. Studies on the epidemiology of sandfly fever in Iran. II. The prevalence of human and animal infection with five phlebotomus fever virus serotypes in Isfahan province. Am J Trop Med Hyg 1977; 26: 288-93.

[34] Tesh RB, Saidi S, Gajdamovic SJ, Rodhain F, Vesenjak-Hirjan J. Serological studies on the epidemiology of sandfly fever in the Old World. Bull World Health Organ 1976; 54: 663-74.

[35] Baldelli F, Ciufolini MG, Francisci D, et al. Unusual presentation of life-threatening Toscana virus meningoencephalitis. Clin Infect Dis 2004; 38: 515-20.

[36] Di Nicuolo G, Pagliano P, Battisti S, et al. Toscana virus central nervous system infections in southern Italy. J Clin Microbiol 2005; 43: 6186-8.

[37] Dionisio D, Valassina M, Ciufolini MG, et al. Encephalitis without meningitis due to sandfly fever virus serotype toscana. Clin Infect Dis $2001 ; 32: 1241-3$.

[38] Valassina M, Valentini M, Valensin PE, Cusi MG. Fast duplex one-step RT-PCR for rapid differential diagnosis of entero- or toscana virus meningitis. Diagn Microbiol Infect Dis 2002; 43: 201-5.

[39] Liu DY, Tesh RB, Travassos Da Rosa AP, et al. Phylogenetic relationships among members of the genus Phlebovirus (Bunyaviridae) based on partial M segment sequence analyses. J Gen Virol 2003; 84: 465-73.

[40] De Lamballerie X, Tolou H, Durand JP, Charrel RN. Prevalence of Toscana virus antibodies in volunteer blood donors and patients with central nervous system infections in southeastern France. Vector borne Zoonotic Dis Larchmont NY 2007; 7: 275-7.

[41] Francisci D, Papili R, Camanni G, et al. Evidence of Toscana virus circulation in Umbria: first report. Eur J Epidemiol 2003; 18: 4579.

[42] Eitrem R, Stylianou M, Niklasson B. High prevalence rates of antibody to three sandfly fever viruses (Sicilian, Naples, and Toscana) among Cypriots. Epidemiol Infect 1991; 107: 685-91.

[43] Schwarz TF, Jager G, Gilch S, Pauli C. Serosurvey and laboratory diagnosis of imported sandfly fever virus, serotype Toscana, infection in Germany. Epidemiol Infect 1995; 114: 501-10. 